\title{
What about industrial water sustainability?
}

\author{
Subhas K. Sikdar
}

Published online: 29 December 2010

(C) Springer-Verlag 2010

Some have said that water will be in the 21 st century what energy was in the 20th century, obviously referring to the issue of meeting adequate demand, availability, and safety issues of these resources for maintaining our living standards. It is true that the availability of fresh water is becoming increasingly a problem with time in many parts of the world, resulting from unsustainable withdrawals from surface and underground resources and from contamination making existing sources unfit. With respect to energy, however, the statement is indeed hyperbolic. If anything, concerns for energy availability will be even more enhanced, as evidenced by rapidly increasing demand and the rush to developing alternative sources of energy for both transportation and power needs all over the world. In the US about half of the water consumption is devoted to power generation, about a third for agriculture, and a relatively smaller amount, 5\%, for industrial purposes. The bulk of the publicly or privately funded research on water technologies has been conducted to satisfy standards for municipal needs (11\% of US water use), and the results of these studies are widely available publicly. The standards for municipal water are roughly similar everywhere. Industrial sectors, however, being many and of different types, technology needs are likewise varied. For instance the water quality needs of the textile dying industry are very different from those of the semiconductor processing industry. The effluents from these two sectors are also different, as are the technologies required to treat these effluents for reclamation purposes.
Deficiency of overall water availability is already causing water scarcer for industrial needs, which is why industry will have to increasingly pay more attention to water sustainability. Thus industry will have to find ways of becoming less dependent on municipal sources. When there is a conflict between the two sectors for access to fresh water, municipal needs will garner higher priority from the governing bodies. This situation requires three actions: (1) minimizing water needs for industrial operations, (2) treating effluents to the standards for repeated recycling and reuse in the same industrial site, and (3) safely disposing the residuals or sludge from the treatment operations. Various modeling techniques have recently been developed and applied industrially, for instance, water pinch technologies and mass exchange network. There are no generic technologies for recycle/reuse, each application requiring means suitable to the specific needs. The advancement made in this regard is still in its infancy. Sludge disposal is a big problem, and techniques such as incineration, encapsulation/stabilization, compaction/drying, and land-filling and others are options to consider. In September 2010, a North Atlantic Treaty Organization (NATO) Advanced Research Workshop was held in Ankara, Turkey, on the sustainability issues of industrial water. Experts from more than 20 countries from North America, Western Europe, East Europe, and the Middle East gathered to share their research with one another. All the presentations are available in the website: http://www. epa.gov/nrmrl/events/event09162010.html. 